\title{
The Time of Diagnosis Impacts Surgical Management but not the Outcome of Patients with Gallbladder Carcinoma
}

\author{
F. Löhe ${ }^{1,2}$, G. Meimarakis ${ }^{1}$, C. Schauer ${ }^{3}$, M. Angele ${ }^{1}$, K. W. Jauch ${ }^{1}$, R.J. Schauer ${ }^{1,3}$ \\ ${ }^{1}$ Surgical Department, Klinikum Grosshadern, Ludwig- Maximilians University of Munich, Germany, \\ ${ }^{2}$ Surgical Department, Academic Hospital Klinikum Landshut, Germany, \\ ${ }^{3}$ Surgical Department, Academic Hospital Klinikum Traunstein, Germany
}

\begin{abstract}
Background: Only $50 \%$ of gallbladder cancers (GBC) are recognized before operation and the remaining tumors are diagnosed during surgery or afterwards by the pathologist. These situations may demand substantial modifications of the proceeding during surgery as well as the need for reoperation in some cases. Therefore, the time of diagnosis may strongly influence the surgical management of $\mathrm{GBC}$ and the prognosis of the patients.

Methods: Records and follow- up of 152 patients with gallbladder carcinoma who underwent surgery between 1980 and 2004 were examined according to the time of diagnosis, TNM staging system, surgical procedures, morbidity and predictors of survival. There were 76 patients with preoperative diagnosis of GBC (50\%; group 1$), 44$ patients with intraoperative diagnosis $(29 \%$; group 2$)$ and 32 patients $(21 \%$; group 3$)$ with postoperatively incidental finding of GBC. In all cases radical resection of the GBC was intended, except in 5 patients from group 1. Surgical procedures comprised from simple cholecystectomy to multivisceral resections.

Results: Overall 5-year survival rate was 7\% with a significantly better median survival in group 3 (53.2 month), when compared to only 6.1 month (group 2) and 5.4 month (group 1), respectively. Findings at operation forced significant modifications of the surgical strategy in $85 \%$. Complete resection of GBC was achieved in 38\% of the patients. Stage- dependent survival was comparable between the groups following $\mathrm{R} 0$ resection. Tumor stage, in particular the nodal status and radicality of the procedure, but not the time of diagnosis were the most powerful predictors of outcome.

Conclusions: Complete tumor resection may provide long-term survival even in locally advanced GBC. Although the time of diagnosis of GBC causes significant changes of the intended procedures during and after surgery, it has no influence on the prognosis provided that radical (R0) resection was accomplished.
\end{abstract}

Key words: Gallbladder cancer, Surgery, Follow up, Prognosis

Abbreviations: GBC, Gallbladder Carcinoma

\section{INTRODUCTION}

Gallbladder carcinoma has a poor prognosis. Five-year survival ranges between $5 \%$ and $13 \%$ with a median survival of less than 6 month $[1,2]$. Because tumor growth is often locally advanced at the time of surgery, no marked improvement of patients outcome was achieved during the last decade [4]. Therefore, once GBC is diagnosed, curative resection can be expected only in $20-40 \%$ of patients [3, 4]. Recent studies suggest the efficacy of a radical approach to enhance survival even in patients with advanced tumor stages [5-7]. However, these reports need careful evaluation because the prognosis strongly depends on the chance to achieve complete tumor resection (R0) [8, 9].

It is specific for $\mathrm{GBC}$ that only about $50 \%$ of the tumors are recognized before an operation [10]. Then, most of the cancers are unresectable due to local or distant tumor growth. Although some studies advocated radical resection in advanced-stage disease, there is no consensus as to the selection of patients considered for surgery [10]. In contrast, intra- or postoperative findings of $\mathrm{GBC}$ were usually associated with smaller tumors and a better prognosis, even though recent literature could demonstrate that preoperative diagnostic workup may fail to predict GBC also in tumor stages T3 and T4 [11, 12]. Particularly with regard to incidental GBC findings by the pathologist, the debate continues about the adequate stage-dependent tumor therapy, when the patients age, morbidity of secondary procedures and 5-year survival rates are taken into account. Therefore, the commonness of incidental GBC, either as an intra- or postoperative finding lies in the need for a substantial switch of the operative strategy during surgery, i.e. from simple cholecystectomy to extended liver resection, or in the need for stratifying patients after removal of the gallbladder to more aggressive, secondary procedures [13-16].

The rarity of GBC limits the ability to perform prospective, randomized studies of therapy. However, there is good evidence from numerous retrospective surveys that tumor stage and radical surgery (R0) are the strongest predictors of survival [17-19]. The purpose of this study is to provide data, how the time of diagnosis of GBC may influence surgical procedures 
as well as the outcome of patients, in particular following radical resection.

\section{Patients And Methods}

Between 1980 and 2004, 196 consecutive patients with GBC were seen at the Surgical Department of the University of Munich. Of these, 165 patients underwent surgery, but only 152 patients were eligible for follow up until July 2006 (Fig. 1). In another 31 patients $(16 \%)$, metastatic disease of GBC was confirmed by biopsies at presentation, yielding a total of 152 patients for data analysis. Mean age was 66.3 years (38-92 years) and there were 93 woman and 59 men in this study (Table 1). Data was collected from chart review and a telephone questionnaire, including patient

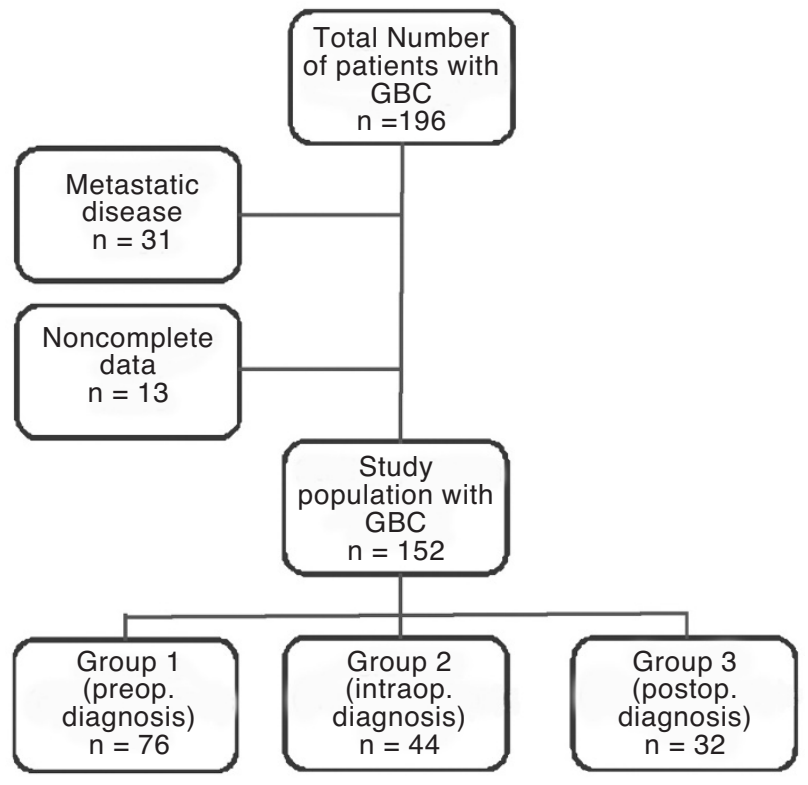

Fig. 1. Management of all patients presenting with gallbladder cancer at our institution.

Note: Patients with serious metastatic disease were excluded from the study because of proven unresectability. Group 1 also contained patients with local metastatic spread which, based on preoperative imaging, was assumed to be suitable for radical resection. demographics, laboratory data, operative management, surgical morbidity, pathologic findings, and length of hospital stay. Histologic examination revealed adenocarcinoma in 141 patients (93\%), adenosquamous tumors in 7 , and squamous carcinoma in 4 patients.

Demographic data as well as the comorbidity of patients were comparable between the groups. The majority of patients showed ASA $1 / 2$ score $(72 \%)$ and liver cirrhosis was absent in most cases (93\%). Data about malignant tumors in the history of some patients included breast cancer (3), prostate cancer (3), and colonic cancer (1) and at the time of admission to our institution, there was no evidence for local or metastatic recurrence of these cancers. GBC was staged according to the TNM classification (UICC; Table 1) [20].

Only 26 patients $(17 \%)$ had tumors limited to the gallbladder wall (T1a, $\mathrm{n}=5$; T1b, $\mathrm{n}=9$; T2, $\mathrm{n}=12$ ) and all of these were recognized only by the pathologist. The remaining patients $(n=126)$ had locally advanced or metastatic cancer.

The most common symptom at presentation was pain $(87 \%$; no difference between the groups). In contrast, mild jaundice (64\%) and weight loss (31\%) were predominantly present in group 1 ( $\mathrm{p}<0.05$ vs. groups 2 and 3). Ninety-four percent of tumors were associated with gallstones. Therefore, routine laboratory tests prior to the operation did not markedly help to identify GBC (Table 2).

The surgical procedure in patients with presumed benign disease was simple cholecystectomy (SCE), either as an open or laparoscopic operation. Early stages of GBC were treated by an "extended cholecystectomy" (ECE) which consisted of an en-bloc removal of the gallbladder with hepatic wedge resection of segments IVb/V, and lymphnode dissection of the ligament. Locally advanced cancers with infiltration of the liver underwent extended liver resection (ELR) and lymphnode dissection of the ligament. In case of involvement by the GBC, bile duct resection (BDR), lymphnode dissection and hepatico-jejunostomy was performed. In some patients multivisceral resections (MVR) were done to achieve radicality. Only laparotomy or palliative surgery was performed when unresectability was suspected. Survival was calculated by the Kaplan-Meier method. Cox univariate and multivariate analysis was performed to determine prognostic factors for survival.

Table 1. TNM (UICC) staging of GBC by time of diagnosis.

\begin{tabular}{r|ccccc}
\hline & UICCI & UICC II & UICC III & UICCIVb & UICCIVb \\
\hline $\begin{array}{r}\text { Group 1 } \\
(\mathbf{n}=\mathbf{7 6})\end{array}$ & 0 & 0 & 15 & 8 & 53 \\
\hline $\begin{array}{r}\text { Group 2 } \\
(\mathbf{n}=\mathbf{4 4})\end{array}$ & 0 & 0 & 10 & 14 & 20 \\
\hline $\begin{array}{r}\text { Group 3 } \\
(\mathbf{n}=\mathbf{3 2})\end{array}$ & 14 & 12 & 6 & 0 & 0 \\
\hline $\begin{array}{r}\text { Total } \\
(\mathbf{n}=\mathbf{1 5 2})\end{array}$ & 14 & 12 & 31 & 22 & 73 \\
\hline
\end{tabular}

Note: In UICC stages I and II GBC is limited to the gallbladder wall (I: T1a/b; II: T2), in UICC stage III lymphnodes are positive (T1-3), in UICC IVa the tumor is locally destructive (T4), and in UICC stage IVb local or distant metastases are present. 
Table 2. Laboratory data at admission to our institution.

\begin{tabular}{l|ccccc}
\hline & $\begin{array}{c}\text { GGT } \\
(\mathbf{U} / \mathrm{l})\end{array}$ & $\begin{array}{c}\text { AP } \\
(\mathrm{U} / \mathrm{l})\end{array}$ & $\begin{array}{c}\text { Bilirubin } \\
(\mathrm{mg} / \mathrm{dl})\end{array}$ & $\begin{array}{c}\text { Leucocytes } \\
(\mathrm{E3} / \mathrm{ml})\end{array}$ & $\begin{array}{c}\text { CRP } \\
(\mathrm{mg} / \mathrm{dl})\end{array}$ \\
\hline Group 1 (n=76) & $104 \pm 78$ & $148 \pm 64$ & $1.9 \pm 3.2$ & $8.6 \pm 7.4$ & $4.9 \pm 6.2$ \\
Group 2 (n=44) & $86 \pm 54$ & $126 \pm 61$ & $1.3 \pm 2.4$ & $9.5 \pm 6.9$ & $9.2 \pm 5.9$ \\
Group 3 (n=76) & $68 \pm 42$ & $97 \pm 54$ & $1.0 \pm 1.2$ & $8.2 \pm 5.6$ & $3.6 \pm 4.8$ \\
\hline Total (n=152) & $87 \pm 43$ & $127 \pm 47$ & $1.5 \pm 2.0$ & $8.9 \pm 5.1$ & $5.4 \pm 4.9$ \\
p & $0.04^{*}$ & 0.7 & $0.02^{* *}$ & 0.8 & 0.2 \\
\hline
\end{tabular}

Note: $*$ group 3 vs. group 1 ; ** group 1 vs. groups 2 and 3 .

\section{RESULTS}

\section{IndicATIONS AND PROCEDURES}

Seventy-six patients out of $152(50 \%)$ were admitted to our institution because of a presumed benign disease. Most of these had gallbladder stones $(\mathrm{n}=71)$ ) and others had concomitant acute $(\mathrm{n}=13)$ or chronic cholecystitis $(\mathrm{n}=21$ ). Diagnostic procedures comprised ultrasound in all patients of this group whereas CT or MRI scans were considered necessary prior to the operation only in 16 patients $(21 \%)$. All 76 patients were subjected to simple cholecystectomy (27 laparoscopic and 49 open procedures).

The pathologist recognized GBC postoperatively in 32 patients (group3) whilst the surgeons did not ap- praise any of these gallbladders suspicious for cancer (Table 3). Fourteen patients had stage I- tumors (T1a, $\mathrm{n}=5$; T1b, $\mathrm{n}=9$ ) and 12 patients were classified as stage II- tumors. Three patients had positive lymphnodes at the cystic duct (stage III) while the carcinoma was limited to the gallbladder wall (T2) and 3 more patients had T3 cancers (one R1 resection). Although the indication for a second procedure was defined as Tstage $\geq \mathrm{T} 1 \mathrm{~b}$, or positive resection margins after SCE, only 12 patients (48\%) underwent definitive cancer surgery.

In 44 patients (group 2) GBC was found incidentally at operation and all of them had already advanced tumor stages (Table 1). Twenty patients were considered unresectable due to bulky lymphnodes in

Table 3. Intended and performed operations (first procedure) by time of diagnosis.

\begin{tabular}{|c|c|c|c|c|c|c|c|}
\hline & Indication & $\begin{array}{l}\text { Intended } \\
\text { procedure }\end{array}$ & $\mathbf{n}$ & $\begin{array}{l}\text { Peformed } \\
\text { procedure }\end{array}$ & $\mathbf{n}$ & $\begin{array}{l}\text { Change of } \\
\text { procedure }\end{array}$ & $\begin{array}{c}\text { Radical (RO) } \\
\text { resection }\end{array}$ \\
\hline $\begin{array}{l}\text { Group } 1 \\
(n=76)\end{array}$ & $\begin{array}{l}\text { Suspected } \\
\text { GBC }\end{array}$ & $\begin{array}{l}\text { SCE } \\
\text { ECE } \\
\text { ELR } \\
\text { BDR } \\
\text { MVR } \\
\text { PALL } \\
\text { LAP }\end{array}$ & $\begin{array}{c}0 \\
5 \\
26 \\
19 \\
21 \\
5 \\
0\end{array}$ & & $\begin{array}{c}0 \\
2 \\
14 \\
4 \\
8 \\
5 \\
43\end{array}$ & $\begin{array}{c}0 \\
60 \% \\
46 \% \\
79 \% \\
62 \% \\
0 \% \\
100 \%\end{array}$ & $\begin{array}{c}- \\
1 / 50 \% \\
8 / 57 \% \\
2 / 50 \% \\
2 / 25 \% \\
0 \% \\
0 \%\end{array}$ \\
\hline $\begin{array}{l}\text { Group } 2 \\
(n=44)\end{array}$ & $\begin{array}{l}\text { Stones } \\
\text { Acute Chol. } \\
\text { Chron. Chol. }\end{array}$ & $\begin{array}{l}\text { SCE } \\
\text { SCE } \\
\text { SCE }\end{array}$ & $\begin{array}{c}30 \\
4 \\
10\end{array}$ & $\begin{array}{l} \\
\\
\text { ECE } \\
\text { ELR } \\
\text { BDR } \\
\text { MVR } \\
\text { PALL } \\
\text { LAP }\end{array}$ & $\begin{array}{c}0 \\
0 \\
0 \\
6 \\
6 \\
10 \\
2 \\
3 \\
17\end{array}$ & $\begin{array}{l}100 \% \\
100 \% \\
100 \%\end{array}$ & $\begin{array}{c}- \\
- \\
- \\
5 / 83 \% \\
5 / 83 \% \\
3 / 30 \% \\
1 / 50 \% \\
0 \% \\
0 \%\end{array}$ \\
\hline $\begin{array}{l}\text { Group } 3 \\
(n=32)\end{array}$ & $\begin{array}{l}\text { Stones } \\
\text { Acute Chol. } \\
\text { Chron. Chol. }\end{array}$ & $\begin{array}{l}\text { SCE } \\
\text { SCE } \\
\text { SCE }\end{array}$ & $\begin{array}{c}12 \\
9 \\
11\end{array}$ & & $\begin{array}{c}12 \\
9 \\
11\end{array}$ & $\begin{array}{l}0 \% \\
0 \% \\
0 \%\end{array}$ & $\begin{array}{c}12 / 100 \% \\
9(100 \%) \\
10 /(91 \%)\end{array}$ \\
\hline $\begin{array}{l}\text { Total } \\
(n=152)\end{array}$ & & & 152 & & 152 & $85 \%$ & $58 /(38 \%)$ \\
\hline
\end{tabular}

Note: SCE, simple cholecystectomy; ECE, extended cholecystectomy; ELR, extended liver resection; $\mathrm{BDR}$, bile duct resection; MVR, multivisceral resection; PALL, palliative procedures; LAP, only laparotomy; Chol., Cholecystitis. 
the ligament $(\mathrm{n}=8)$, liver metastasis $(\mathrm{n}=6)$, and peritoneal implants of the GBC $(n=6)$. In the remaining patients, the surgical strategy was changed immediately at operation and radical resection of the tumor was attempted. The procedures performed, included all options of resective surgery as demonstrated in Table 3.

The remaining patients $(n=76)$ presented prior to surgery pathological findings which were in accordance with GBC disease (group 1). Five patients had intestinal obstruction as the main symptom and thus required palliative surgery (Table 3 ). In contrast, CTand MRI findings of the remaining patients with suspected GBC were evaluated as suitable for a radical approach. However, in 44 patients of group $1(58 \%)$ the tumor size and infiltration pattern as well as the intraoperative detection of distant metastasis (liver, $\mathrm{n}=21$; peritoneum, $\mathrm{n}=14$; liver and peritoneum, $\mathrm{n}=9$ ) did not allow curation from GBC, and obliged the surgeon to terminate the operation as a diagnostic procedure. The remaining patients $(n=32)$ underwent radical surgery which was strongly dependent on differential types of local tumor growth (Table 3).

The R- status, as indicated in Table 3 describes radicality at first operation. Twenty-five patients of group 3 had tumor stages which required re- operation but only 12 of them were referred to additional surgery. In that collective, complete tumor resection (R0) was achieved in all cases (ECE, $\mathrm{n}=9$; ELR, $\mathrm{n}=3$ ). However, patients with suspected GBC (group 1) had a significantly $(p<0.05)$ higher risk for incomplete tumor control after surgery (83\%) when compared to patients with GBC detected at operation $(69 \%)$ or as an incidental finding by the pathologist $(3 \%)$.

\section{Perioperative Parameters}

There was no mortality in the study population, although it is sometimes a challenge for the surgical team as well as the anaesthesiologist to cope with a radical change of the surgical procedure at operation $[3,10]$. However, as Table 4 indicates there were no marked differences seen when perioperative data of groups 1 and 2 are compared. Blood loss as well as the operating time and complication rates were similar in both groups, indicating no additional risk for patients with incidental GBC finding at operation. In all patients of group 2, a definitive procedure was aimed at the first operation so that secondary interventions were avoided. Mean hospital stay was 12.2 days in group 1 (7-31 days), 11.8 days in group 2 (6-24), and 4.8 days (2-8) in group 3.

\section{SURVIVAL}

The overall 1-, 3,- and 5- year survival rates of the 152 patients were dismal with $43 \%, 24 \%$, and $7 \%$, respectively. This is the result of a highly metastatic potential of GBC which resulted in lymphnode involvement in $71 \%$ and systemic tumor spread in $49 \%$ of the analyzed patients. These advanced tumors did not allow a cumulative R0 resection rate beyond $38 \%$. As demonstrated in Table 3, we found a significant correlation between the time of diagnosis and the radicality $(\mathrm{R}$ status), indicating a poorer chance of complete tumor resection with respect to the procedures performed. Figure 2 illustrates the dependency of survival from the groups. It is clearly demonstrated that in univariate analysis the time of recognizing GBC has a highly significant impact on the probability for survival as shown by median survival times of 53.2 month (group 3), 6.1 month (group 2), and 5.4 month (group 1).

The median survival for the 94 patients with unresectable tumors (R1/R2) was 5.1 month with only 1 patient alive beyond 2 years (26 month). For those resected, the 1-, 3,- and 5-year survival was $79 \%, 47 \%$, and $26 \%$, respectively. Interestingly, when the patients of groups 1 - 3 who underwent radical tumor resection (R0) are compared, we found no differences with regard to the prognosis when GBC was an incidental finding (Table 5). In contrast, patients with incomplete tumor resection $(\mathrm{R} 1 / 2)$ showed median survival times of only 4.8 month (R1 resection) and 3.2 month (R2 resection).

As demonstrated in Table 5, the time of diagnosis has no effect on the outcome of patients once complete tumor resection was possible. This finding was confirmed in multivariate analysis which showed the UICC stage $(p<0.001)$ and radicality of the procedure $(p<0.001)$ as the only independent predictors of survival. In contrast, the parameter "time of diagnosis" did not have the power as a prognostic factor of survival ( $p=0.4$; Cox regression analysis).

Table 4. Perioperative parameters and morbidity by groups 1 and 2 .

\begin{tabular}{|c|c|c|c|c|c|c|}
\hline & ECE & ELR & BDR & MVR & PALL & LAP \\
\hline \multicolumn{7}{|l|}{ Group 1 ( $n=76)$} \\
\hline OP time (min) & $112 ; 125$ & $178 \pm 98$ & $148 \pm 62$ & $204 \pm 44$ & $94 \pm 32$ & $29 \pm 34$ \\
\hline \multirow[t]{2}{*}{ Blood loss (I) } & 0.4 & 1.1 & 0.5 & 1.3 & 0.3 & 0.04 \\
\hline & $(0.05 ; 0.8)$ & $0.2-2.7$ & $0.1-1.4$ & $0.2-2.4$ & $0.2-0.9$ & $0-1.8$ \\
\hline Morbidity (\%) & 0 & 21 & 31 & 30 & 20 & 10 \\
\hline \multicolumn{7}{|l|}{ Group $2(n=44)$} \\
\hline OP time (min) & $123 \pm 34$ & $191 \pm 105$ & $154 \pm 74$ & $211 ; 205$ & $86 \pm 15$ & $34 \pm 18$ \\
\hline \multirow[t]{2}{*}{ Blood loss (I) } & 0.4 & 1.3 & 0.7 & 1.8 & 0.2 & 0.02 \\
\hline & $0.03-1.9$ & $0.3-2.2$ & $0.1-1.8$ & $1.1 ; 2.6$ & $0.1-0.5$ & $0-0.4$ \\
\hline Morbidity (\%) & 17 & 24 & 25 & 50 & 33 & 12 \\
\hline
\end{tabular}




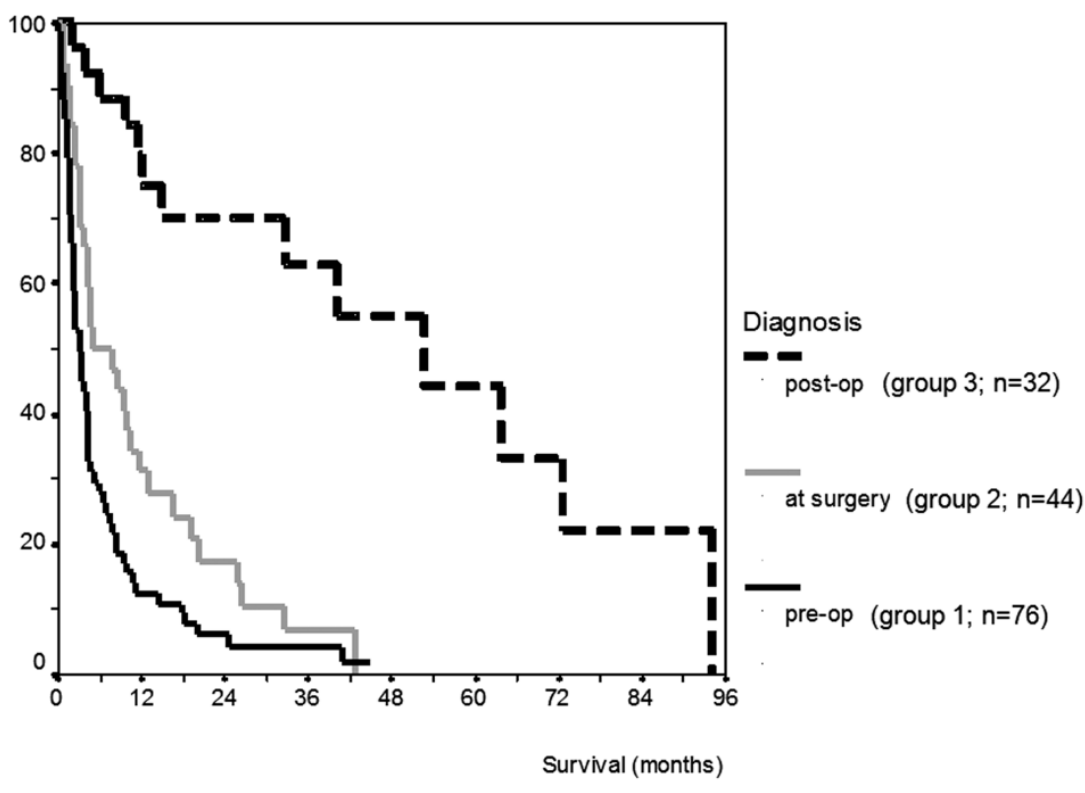

Fig 2. Survival by time of diagnosis of GBC.

Note: $\mathrm{p}<0.001$ (group 3 vs. groups $1 / 2$ ) and $\mathrm{p}<0.05$ (group 2 vs. group 1 ).

Table 5. Survival of patients with complete resection (R0) of GBC.

\begin{tabular}{r|ccccc}
\hline & $\mathbf{n}$ & $\mathbf{N +}$ & $\mathbf{M +}$ & $\begin{array}{c}\text { Survival } \\
\text { (month) }\end{array}$ & $\begin{array}{c}\text { Survival } \\
\text { (5 years) }\end{array}$ \\
\hline Group 1 (76) & & & & & \\
T3 & 9 & 6 & 2 & 21.9 & 19.9 \\
T4 & 4 & 3 & 1 & 17.2 & 12.2 \\
\hline Group 2 (44) & & & & & \\
T3 & 7 & 5 & 2 & 23.8 & 21.1 \\
T4 & 7 & 5 & 4 & 18.9 & 11.8 \\
\hline Group 3 (32) & & & & & \\
T1 & 14 & 0 & 0 & 67.8 & 79.3 \\
T2 & 15 & 3 & 0 & 58.3 & 68.9 \\
T3 & 3 & 1 & 1 & 23.4 & 26.0 \\
\hline
\end{tabular}

Note: Given are median survival times.

\section{Discussion}

Gallbladder carcinoma carries a poor prognosis, and the only chance for cure lies in early detection and complete resection. However, the extent of surgical procedures remains controversial, particularly after incidental findings or in advanced stages of disease [13, $21,22]$. Some reasons for this are the lack of a uniform classification of staging systems in previous reports [23-25] and a different use of terms like "extended cholecystectomy" and „extended resection“ which included various surgical procedures in some studies $[7,23,26]$. The 5 - year survival rate following surgery for $\mathrm{GBC}$ is reported to be $5-13 \%$ in the recent literature $[1,2,27]$ except a study of a small number of cases [2]. The aim of our retrospective study was to highlight the perioperative situation, the surgeon is confronted with: (1) ad hoc decision at incidental findings of GBC during operation about the extent of further procedure, and (2) stratification of patients with postoperatively found GBC to a second operation. In particular, it was of interest if the time of diagnosis may influence radicality of surgical procedures and the prognosis of patients.

The diagnosis of GBC is difficult because of the lack of reliable diagnostic methods $[11,12,28]$ and the unspecific symptoms of patients who, to a considerable extent presented in this study with gallbladder stones $(94 \%)$ or cholecystitis $(22 \%)$. Furthermore, in 16 out of 92 patients $(17 \%)$ who underwent CT or MR imaging prior to the operation GBC was not detected even though T3 and T4 tumors were present. Laboratory data usually are also of limited significance as reported earlier and shown in Table 2 [29]. Consequently, it seems specific that GBC is just partly recognized at diagnostic work up before surgery and that the remaining carcinomas are detected not until as by the surgeon at operation or by the pathologist thereafter. In this study, GBC was suspected in $50 \%$ of the patients preoperatively, which is in line with recent literature $[10,30]$. In all other cases, diagnosis was made at the time of surgery (29\%) or postoperatively (21\%).

There exists evidence in recent literature that tumor stage and radical resection are significant predictors of 
survival [17-19, 31]. That requires special consideration as to the indication to extended surgery, in particular when GBC is an incidental finding. We could demonstrate that the time of diagnosis of GBC has a strong influence on tumor stages: significantly more patients with stage III and IV disease were observed in groups 1 (suspected GBC) and 2 (incidental finding at operation). Ninety-three percent and $72 \%$ had lymph node involvement in groups 1 and 2, respectively, whereas only 3\% were affected in group 3. Local or distant metastasis was present in $70 \%$ of patients in group 1, 45\% (Group 2), and 3\% (group 3).

Therefore, it is obvious that the tumor stage directly impairs the chance for radical cure of the disease. Consequently, the rates of complete tumor resections (R0) varied significantly between the groups, showing the best result in group $3(\mathrm{R} 0 ; 100 \%)$ and disappointing results in group 2 (R0;32\%), and group 1 (R0;17\%) which is for the most part consistent with earlier work $[28,32]$. The indication to secondary procedures after SCE was based on data which demonstrated venous, lymphatic, or perineural tumor invasion also in T1b stages, although lymph node involvement is rare in T1 stage [33] and some authors refuse additional surgery $[23,33,34]$. In our series, only 5 patients had T1a disease and 9 were staged as T1b. All of them were staged as node- negative. Five patients with T1b stage underwent a second procedure and no residual tumor was found. Five- year survival of patients with T1 disease was $79 \%$. In contrast, we found a $48 \%$ risk of positive nodes as well as a $21 \%$ risk of tumor spread in T2 cases which clearly demands a more radical approach than SCE [30].

In the present study, only $15 \%$ of the operations were accomplished as intended, the rest of the patients underwent either a dramatic change of the procedure or a second intervention. All the more, careful evaluation of the tumor stage at operation, the age and prognosis of the diseased patients and the additional risk of extended resections should be in mind of the surgeon [27]. Although we had no mortality in our patients, some indications for extended tumor resections seemed too optimistic with regard to $\mathrm{R} 0$ rates of only $31 \%$ in group 2 and $17 \%$ in group 1 . Moreover, we and others could demonstrate that not only the tumor stage, but also the pattern of tumor growth, and consecutively the kind of surgical procedure has a strong impact on radicality [6]. Infiltration or local tumor spread to the liver usually required ELR whereas the involvement of the common bile duct demanded resection and hepatico-jejunostomy. In our series, we achieved complete resection after ELR in 13 out of 20 cases $(65 \%)$ compared to only $36 \%(5 / 14)$ following BDR. From similar findings, Miyazaki et al. developed a stratification system for patients with significantly different prognoses due to tumor localization and the involvement of adjacent organs [32]. Some authors suggest extended lymphnode resection for radical treatment of GBC in these cases $[6,8,23]$. However, we and others [34] precluded patients with proven involvement of coeliac, superior mesenteric and paraaortic lymph nodes from radical resection because the prognosis seems similar to metastatic disease [7]. Extended resections were performed in our series with a low morbidity which is in line with recent reports, demonstrating low mortality and complication rates after major liver resections even in the older population [35].

Complete macroscopic and microscopic resection of the gallbladder including adjacent tissue of various extent is a prerequisite for long- term survival, particularly in advanced tumor stages $[17,27]$. Our findings support this contention, demonstrating gross tumor remnants (R2) as well as microscopically positive tumor margins (R1) as significantly negative predictors of survival. As we could show that the time of diagnosis of GBC strongly influences surgical procedures and radicality, it was of special interest if survival was dependent on the time of diagnosis when complete tumor resection was accomplished. Interestingly, we observed comparable median and five- year survival rates, regarding T3 and T4- staged GBC of groups 1 and 2. Patients with T3 cancer had a median survival time of about 22 month whereas in cases with T4 stage, the prognosis was decreased to approximately 18 month. Taking the median survival of patients with unresected GBC into account, the survival benefit of those undergoing radical surgery (R0) is almost about 20 month. Therefore, it seems justified to subject patients with incidental findings of advanced GBC to aggressive surgery at the same operation [3], in particular because of the low morbidity as demonstrated in this series. We had only 3 patients with T3staged GBC in the postoperative findings, one had positive lymphnodes and another had a single liver metastasis next to the gallbladder bed. Reoperation resulted in complete tumor control, but median survival was also disappointing with 23.4 month. Although there is no group in this study undergoing observation alone for comparison, it is certain that residual disease would lead to recurrence and death within 6 month [23].

In conclusion, the present study confirms earlier reports which demonstrated a significant impact of the tumor stage and a radical resection of GBC on survival [27]. This anaylsis additionally proved that the time of diagnosis has no influence on the prognosis of patients after radical resection. However, substantial decisions concerning the indication, the framing of the approach to resection, the expected morbidity and survival time are requested by the surgeon. Special attention has to be drawn in the future on a careful imaging before surgery to avoid R1/R2- resections.

\section{REFERENCES}

1. Cubertafond P, Gainant A, Cucchiaro G. Surgical treatment of 724 carcinomas of the gallbladder. Results of the French Surgical Association Survey. Ann Surg 1994:219:275-280.

2 Bartlett DL, Fong Y, Fortner JG, Brennan MF, Blumgart LH. Long-term results after resection for gallbladder cancer. Ann Surg 1996;224:639-646

3 Sikora SS, Singh RK. Surgical strategies in patients with gallbladder cancer: nihilism to optimism. J Surg Oncol 2006;93:670-681

4 Miller G, Jarnagin WR. Gallbladder carcinoma. Eur J Surg Oncol 2008;34:306-312 
5 Foster JM, Hoshi H, Gibbs JF, Iver R, Javle M, Chu O, Kuvshinoff B. Gallbladder cancer: defining the indication for primary radical resection and radical re-resesection. Ann Surg Oncol 2007;14:833-840

6 Chijiiwa K, Tanaka M. Carcinoma of the gallbladder: an appraisal of surgical resection. Surgery 1994;115:751-756

7 Todoroki T, Takahashi H, Koike N, Kawamoto T, Kondo T, Yoshida $\mathrm{S}$ et al. Outcome of aggressive treatment of stage IV gallbladder cancer and predictors of survival. Hepatogastroenterology 1999;46:2114-2121

8 Nakamura S, Shohachi S, Hiroyuki K, Shozo B, Satoshi B. Outcome of extensive surgery for TNM stage IV carcinoma of the gallbladder. Hepatogastroenterology 1999;46:2138-2143

9 D`Angelica M, Dalai KM, Dematteo RP, Fong Y, Blumgart LH, Jarnagin WR. Analysis of the extent of resection for adenocarcinoma of the gallbladder. Ann Surg Oncol 2009;16:806-816

10 Akatsu T, Masakazu U, Shimazu M, Wakabayashi G, Aiura $\mathrm{K}$ et al. Long-term survival of patients with gallbladder cancer detected during or after laparoscopic cholecystectomy. World J Surg 2005;29:1106-1109

11 Kim SJ, Lee JM, Lee JY, Kim SH, Han JK, Choi BI, Choi JY. Analysis of enhancement pattern of flat gallbladder wall thickening on MDCT to differentiate gallbladder cancer from cholecystitis. Am J Roentgenol. 2008;191:765-71

12 Ouchi K, Sugawara T, Ono H, Fujiya T, Kamiyama Y, Kakugawa Y, Mikuni J, Endo K. Diagnostic capability and rational resectional surgery for early gallbladder cancer. Hepatogastroenterology 1999;46:1557-1560

13 Mekeel KL, Hemming AW. Surgical management of gallbladder carcinoma: a review. J Gastrointest Surg 2007;11:1188-1193

14 Kang Cm, Choi GH, Park SH, Kim KS, Choi JS, Lee WJ, Kim BR. Laparoscopic cholecstectomy only could be an appropriate treatment for selected clinical R0 gallbladder carcinoma. Surg Endosc 2007;21:1582-1587

15 Frauenschuh D, Greim R, Kraas, How to proceed in patients with carcinoma detected after laparoscopic cholecystectomy. Langenbecks Arch Surg 2000;385:495-500

16 WisePE, Shi YY, Washington MK, Chapman WC, Wright $\mathrm{JK}$, et al. Radical resection improves survival for patients with pT2 gallbladder carcinoma. Am Surg 2001;67:10411047

17 Kayahara M, Nagakawa T, Nakagawara H, Kitagawa, Ohta T. Prognostic factors for gallbladder cancer in Japan. Ann Surg 2008;248:807-814

18 Shimizu H, Kimura F, Yoshidome H, Ohtsuka M, Kato A, Yoshitomi H, Nozawa S, Furukawa K et al. Aggressive surgical approach for stage IV gallbladder carcinoma based on Japanese Society of Biliary Surgery classification. J Hepatobiliary Pancreat Surg 2007;14:358-365

19 Fong Y, Jarnagin W, Blumgart LH. Gallbladder cancer: comparison of patients presenting initially for definitive operation with those presenting after prior noncurative intervention. Ann Surg 2000;232:557-569

20 TNM-Klinische Klassifikation UICC 1997. Springer; Berlin, Heidelberg, New York, Tokyo, 1997

21 Goetze TO, Paolucci V. Immediate re-resection of T1 incidental gallbladder carcinomas: a survival analysis of the German registry. Surg Endosc 2008;22:2462-2465

22 Orth K, Beger HG. Gallbladder carcinoma and surgical treatment. Langenbecks Arch Surg 2000;385:501-508

23 Donohue JH, Nagorney DH, Grant CS, Tsushima K, Ilstrup DM, Adson MA. Carcinoma of the gallbladder. Does radical resection improve outcome? Arch Surg 1990;125:237-241
24 Nevin JE, Moran TJ, KayS, King R. Carcinoma of the gallbladder. Cancer 1976;37:141-148

25 Matsumoto Y, Fujii H, Aoyama H, Yamamoto M, Sugahara K, Suda K. Surgical treatment of primary carcinoma of the gallbladder based on the histological analyasis of 48 surgical specimens. Am J Surg 1992;163:239-245

26 Tsukada K, Hatakeyama K, Kurosaki I, Uchida K, Shirai $\mathrm{Y}$, Muto $\mathrm{T}$ et al. Outcome of radical surgery for carcinoma of the gallbladder according to the TNM stage. Surgery 1996;120:816-821

27 Lai CH, Lau WY. Gallbladder cancer: a comprehensive review. Surgeon 2008;6:101-110

28 Paolucci V, Neckel M, Götze T. Unsuspected gallbladder carcinoma. The CAE-S/CAMIC registry. Zentralbl Chir 2003;128:309-312

29 Lowenfels AB, Maisonneuve P, Boyle P, Zatonski WA. Epidemiology of gallbladder cancer. Heptatogastroenterology 1999;46:1529-1532

30 Wakai T, Shirai Y, Hatakeyama K. Radical second resection provides survival for patients with T2 gallbladder carcinoma first discovered after laparoscopic cholecystectomy. World J Surg 2002;26:867-871

31 Kolb A, Kleeff, Friess H, Büchler MW. The effect of R1 resection in the hepatobioliary pancreatic system. Chirurg 2007;78:802-809

32 Yamaguchi K, Chijiwa K, Saiki S, Nishihara K, Takashima M, Kawakami $\mathrm{K}$ et al. Retrospective analysis of 70 operations for gallbladder carcinoma. Br J Surg 1997;84:200-204

33 De Aretxabala XA, Roa IS, Burgos LA, Araya JC, Villaseca MA, Silva. Curative resection in potentially resectable tumours of the gallbladder. Eur J Surg 1997;163:419-426

34 Shirai Y, Yoshida K, Tsukada K, Muto T. Inapparent carcinoma of the gallbladder. An appraisal of radical second operation after simpe cholecysectomy. Ann Surg 1992;215:326-331

35 Miyazaki M, Itoh H, Ambiru S, Shimizu H, Togawa A, Gohchi E et al. Radical surgery for advanced gallbladder carcinoma. Br J Surg 1996;83:478-481

36 Noie T, Kubota K, Abe H, Kimura W, Harihara Y, Takayama T, Makuuchi M. Proposal on the extent of lymph node dissection for gallbladder carcinoma. Hepatogastroenterology 1999;46:2122-2127

37 Shimada H, Endo I, Nakano A Izumi T, Nakagawara G. the role of lymph node dissection in the treatment of gallbladder carcinoma. Cancer 1997;79:829-899

38 Adam R, Chiche L, Aloia T et al. Hepatic resection for noncolorectal nonendocrine liver metastases. Ann Surg 2006;244:524-535

Received: March 31, 2009 / Accepted: April 22, 2009

Address for correspondence:

Rolf J. Schauer, M.D.

Surgical Department

Klinikum Traunstein

Cuno-Niggl-Str. 3

83278 Traunstein

Germany

Fax: $\quad 0861-705-1470$

Phone: 0861-705-1201

Email: rolf.schauer@klinikum-traunstein.de 